\title{
Altered Lipid Composition in a Non-differentiating Derivative of Streptomyces hygroscopicus
}

\author{
By UDO GRÄFE, * GÜNTHER REINHARDT, DIETRICH KREBS, \\ MARTIN ROTH AND DIETER NOACK \\ Akademie der Wissenschaften der DDR, Forschungszentrum für Molekularbiologie und Medizin, \\ Zentralinstitut für Mikrobiologie und experimentelle Therapie, Beutenbergstrasse 11, PO Box 73, \\ DDR-6900 Jena, German Democratic Republic
}

(Received 16 July 1981; revised 8 November 1981)

\begin{abstract}
The turimycin-producing Streptomyces hygroscopicus strain JA6599/NG60-93 $\left(\mathrm{Tur}^{+} \mathrm{Amy}^{+}\right.$) and strain $\mathrm{CC1}$, which is unable to produce antibiotic and aerial mycelium (Tur ${ }^{-} \mathrm{Amy}^{-}$), were compared with respect to their mycelial enzyme activities and cellular lipid composition. Changed activities of six enzymes of intermediary metabolism during submerged growth of strain $\mathrm{CCl}$ on chemically defined medium attest to alterations of the life cycle. In addition, strain $\mathrm{CCl}$ contained decreased amounts of 12-methyltetradecanoic acid in relation to 14methylpentadecanoic acid (isopalmitic acid) and displayed a quantitatively altered phospholipid composition.
\end{abstract}

\section{INTRODUCTION}

Plasmids are known to play an important role in the control of differentiation and secondary metabolism of streptomycetes (Hopwood, 1978). However, at present the biochemical mechanism of plasmid control is unknown (Chater, 1979; Okanishi, 1979). For further study of these problems it should be useful to compare plasmid-carrying strains with their plasmid-free derivatives. During continuous culture the turimycin-producing Streptomyces hygroscopicus strain JA6599/NG60-93 ( Tur $^{+}$Amy $^{+}$) segregated non-differentiating clones with high frequency. It was suggested that this segregation might be caused by loss of extrachromosomal DNA (Roth \& Noack, 1982). The non-differentiating derivatives were found to be altered with respect to turimycin production ( $\left.\mathrm{Tur}^{-}\right)$, formation of aerial mycelium $\left(\mathrm{Amy}^{-}\right)$and resistance to turimycin $\left(\mathrm{Tur}^{\mathrm{S}}\right.$ ) compared with their progenitor strain ( $\mathrm{Tur}^{+} \mathrm{Amy}^{+} \mathrm{Tur}^{\mathrm{R}}$ ) (Roth et al., 1982). In an attempt to ascertain the cellular target of control of differentiation in $S$. hygroscopicus, we have compared the mycelial enzyme activities and lipid composition of the original strain NG60-93 and its nondifferentiating derivative $\mathrm{CC} 1$ during cultivation on a chemically defined medium.

\section{METHODS}

Organisms. Strains NG60-93, NG33-354 and R27-158, mutants of the wild-type strain Streptomyces hygroscopicus JA 6599, were obtained from the strain collection of the Zentralinstitut für Mikrobiologie und experimentelle Therapie, Jena. The non-differentiating derivative CCl was described recently (Roth et al., 1982).

Media: A complex agar medium (CM), AL53 agar (Roth \& Noack, 1982) was used for both the propagation of the strains and the cultivation of surface mycelium. Mineral salts medium (Roth \& Noack, 1982) containing $10 \mathrm{~g}$ glucose $1^{-1}, 0.5 \mathrm{~g} \mathrm{NH}_{4} \mathrm{Cl}^{-1}$ and $15 \mathrm{~g}$ agar (Difco) $1^{-1}$ was used for the production of mycelium on minimal agar medium (MM). The medium for submerged culture (SM) contained $\left(\mathrm{g} \mathrm{l}^{-1}\right)$ : glucose, 25 (sterilized separately by heat); DL-alanine, 1; DL-aspartic acid, 1; L-glutamic acid, 1; $\left(\mathrm{NH}_{4}\right)_{2} \mathrm{SO}_{4}, 1 ; \mathrm{NaCl}, 2 \cdot 5 ; \mathrm{KH}_{2} \mathrm{PO}_{4}, 0 \cdot 5 ; \mathrm{FeCl}_{3}$, $0.005 ; \mathrm{MgCl}_{2} .6 \mathrm{H}_{2} \mathrm{O}, 0.04 ; \mathrm{MnSO}_{4} .2 \mathrm{H}_{2} \mathrm{O}, 0.02 ; \mathrm{CaCl}_{2} .6 \mathrm{H}_{2} \mathrm{O}, 2 ; \mathrm{CaCO}_{3}, 1 ; \mathrm{pH} 6.2$ (prior to sterilization).

Growth conditions. Agar slant cultures were prepared as described previously (Roth \& Noack, 1982) except that strain $\mathrm{CCl}$ was incubated for $5 \mathrm{~d}$ only. Spores or mycelium from agar slant cultures were spread on the surface of $\mathrm{CM}$ and $\mathrm{MM}$ medium and incubated for $8 \mathrm{~d}$ at $28^{\circ} \mathrm{C}$. All submerged cultivations were carried out in $500 \mathrm{ml}$ glass flasks containing $80 \mathrm{ml}$ medium on rotary shakers $\left(240 \mathrm{rev} \cdot \mathrm{min}^{-1}, 5 \mathrm{~cm}\right.$ stroke $)$. For inocula, spores or mycelium 
from agar slant cultures were grown at $27^{\circ} \mathrm{C}$ for $48 \mathrm{~h}$ and then $3 \mathrm{ml}$ portions were transferred to $80 \mathrm{ml} \mathrm{SM}$ medium. These cultures were shaken at $25^{\circ} \mathrm{C}$.

Harvesting of mycelium and disintegration. Mycelium was scraped off the surface of agar plates or collected from submerged cultures by suction filtration. Mycelial extracts were prepared by suspending deep-frozen mycelium (washed and then stored for 1 week at $-25^{\circ} \mathrm{C}$ ) in Tris/ $\mathrm{HCl}$ buffer $(0 \cdot 1 \mathrm{M}, \mathrm{pH} \mathrm{7.2)}$ and subjecting it to sonic treatment for $3 \times 30 \mathrm{~s}$ (Labsonic 1510 , Braun Melsungen, F.R.G.) at $0{ }^{\circ} \mathrm{C}$. The disrupted cells were centrifuged at $0{ }^{\circ} \mathrm{C}$ for $15 \mathrm{~min}(23000 \mathrm{~g})$ and the supernates were used as crude mycelium extracts for the assays.

Measurements of enzyme activities. Enzyme activities were assayed by standard procedures; all measurements were performed in triplicate. NADP-glutamate dehydrogenase (EC 1.4.1.4) was measured according to Schmidt (1970), NAD-alanine dehydrogenase (EC 1.4.1.1) according to Wiame et al. (1962), NAD-malate dehydrogenase (EC 1.1.1.37) according to Bergmeyer (1970), NADP-isocitrate dehydrogenase (EC 1.1.1.42) according to Bernt \& Bergmeyer (1970), glutamine synthetase (EC 6.3.1.2) according to Kohlhaw et al. (1965), NADPdependent glucose-6-phosphate dehydrogenase (EC 1.1.1.49) according to Löhr \& Waller (1970) and protein by the Lowry method. Turimycin was assayed by means of the standard agar plate diffusion test using Bacillus subtilis ATCC 6633 as the test organism.

Lipid extraction and analysis. Lipid material was extracted from the freshly harvested mycelium by treatment with methanol/ $\mathrm{CHCl}_{3}(2: 1, \mathrm{v} / \mathrm{v})$ for $48 \mathrm{~h}$ at room temperature (Kates, 1972). The extraction was repeated for the quantitative estimations. The mycelial content of lipids was estimated gravimetrically. The lipids were obtained from the mycelium extracts by the method of Folch (Kates, 1972). Samples were either subjected to TLC or treated with methanolic $\mathrm{HCl}\left(25 \mathrm{~g} \mathrm{HCl}^{-1}, 48 \mathrm{~h}\right)$ to prepare the methyl esters of fatty acids. TLC was carried out on silica gel sheets (precoated, Merck) using $\mathrm{CHCl}_{3} /$ methanol/water $(65: 25: 4$, by vol.) as the solvent for the separation of polar lipids. Authentic samples of phosphatidylethanolamine and cardiolipin (Koch-Light) were run in parallel. For the identification of ornithinolipids, the appropriate zones were scraped off the plates, eluted and hydrolysed for $2 \mathrm{~d}$ with $6 \mathrm{M}-\mathrm{HCl}$ at $110^{\circ} \mathrm{C}$ in sealed glass tubes. The products of hydrolysis were subject to two-dimensional chromatography on precoated cellulose sheets (Merck) according to Arx \& Neher (1963). Aminolipids were stained with ninhydrin/collidine reagent while the phospholipids were detected by means of Vaskovski's reagent (Kates, 1972). Separation of neutral and polar lipid fractions was achieved by preparative column chromatography on silica gel $60(0.065-0.2 \mathrm{~mm}$, Merck) according to Kates (1972).

Gas chromatography. GLC of fatty acid methyl esters was carried out with a gas chromatograph model GCHF$18 \cdot 3$ (VEB Chromatron Berlin, G.D.R.) equipped with a flame-ionization detector. Glass columns $(3 \mathrm{~m} \times 3 \mathrm{~mm}$ i.d.) were employed, which were filled with $3 \%$ (w/w) DEGS on Chromosorb G (80-100 mesh; Serva, Heidelberg, F.R.G.) and operated isothermally at $165^{\circ} \mathrm{C}$. The injection temperature was $220^{\circ} \mathrm{C}$, the detector temperature $200{ }^{\circ} \mathrm{C}$, and nitrogen $\left(35 \mathrm{ml} \mathrm{min}{ }^{-1}\right)$ was the carrier gas. Peaks were identified by comparing their retention times with those of authentic standards of fatty acid methyl esters (Serva). The relative proportions were calculated on the basis of weighed peak areas.

\section{RESULTS}

\section{Life cycles of strains NG60-93 and CC1 during submerged growth}

During submerged cultivation on SM medium, mutant $\mathrm{CC} 1$ differed from the original strain NG60-93 with respect to both its ability to produce the macrolide antibiotic turimycin and its growth pattern (Fig. 1). Thus, strain $\mathrm{CC1}$ displayed prolonged mycelial development and, in contrast to the parent, the mycelium did not settle in the fermentation flask indicating altered morphology of the submerged hyphae (Roth et al., 1982). Differences in the life cycles of strains NG60-93 and $\mathrm{CCl}$ were also shown by changed activities of some enzymes of carbohydrate and amino acid metabolism as well as of the citric acid cycle (Fig. 1). In several independent experiments, strain $\mathrm{CC} 1$ displayed higher activities of glutamate and glutamine synthetase and other enzyme activities were also changed.

\section{Lipid composition during submerged and surface culture}

The thin-layer chromatograms of aminolipid and phospholipid fractions of submerged mycelium of strains NG60-93 and CC1 are shown in Fig. 2. Phosphatidylethanolamine, two different ornithinolipids (designated ornithinolipids 1 and 2), cardiolipin and a further phospholipid, probably phosphatidylinositol, were the main constituents of mycelial lipids of both strains. As found earlier (Batrakov et al., 1978), addition of phosphate to the SM medium $\left(0.4 \% \mathrm{KH}_{2} \mathrm{PO}_{4}\right.$ added at time 0 ) led to complete suppression of ornithinolipid formation (U. Gräfe \& $G$. Reinhardt, unpublished observation; Konova et al., 1978). TLC on silica gel sheets (Fig. 2) gave 


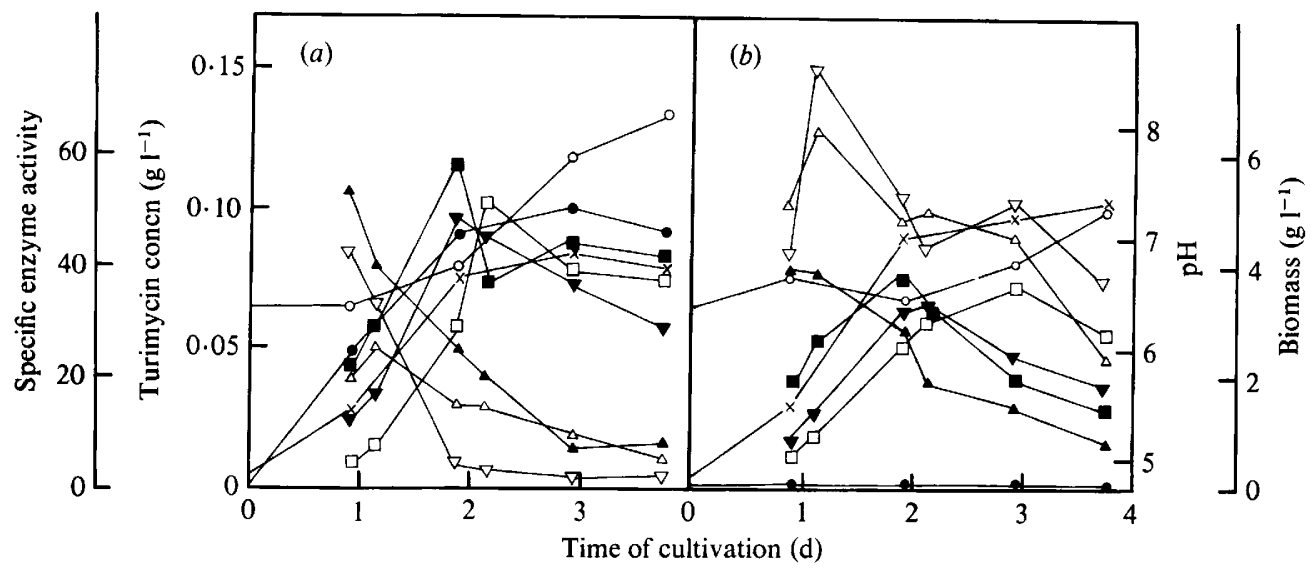

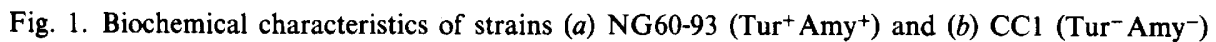
during growth on SM medium: biomass $(x)$; $\mathrm{pH}$ of the culture medium $(O)$; turimycin concentration in the medium (O); specific enzyme activity [expressed as $\mathrm{nmol} \mathrm{min}^{-1}$ ( $\mathrm{mg}$ extracted mycelial protein $\left.^{-1}\right]-0.01 \times$ NAD-malate dehydrogenase $(\square), 0.1 \times$ NADP-isocitrate dehydrogenase $(\square)$, NADP-glutamate dehydrogenase $(\triangle), 0 \cdot 1 \times$ NAD-alanine dehydrogenase $(\Lambda)$, glutamine synthetase $(\nabla), 0.5 \times$ NADP-glucose-6-phosphate dehydrogenase $(\nabla)$.

the same $R_{F}$ values for cardiolipin and ornithinolipid 1. However, on silica gel $\mathrm{H}$ plates (Merck) both spots could be well separated (Kates, 1972). The lipids of both strains showed no striking difference in their qualitative composition although the ratios of their components were altered. Thus, during the growth of strain $\mathrm{CCl}$ there was a reduction in the amount of phosphatidylethanolamine while the amount of ornithinolipid 2 increased. Similar lipid compositions were found in mycelium harvested from agar plate cultures on CM and MM medium, except that ornithinolipid 2 was not present. Differences were also detected in the total lipid content of submerged cultures grown for $72 \mathrm{~h}$ in SM medium. In this case strain $\mathrm{CC} 1$ contained about twice as much lipid material $(2 \cdot 1 \%, \mathrm{w} / \mathrm{w}$, of mycelial dry weight) as did the parent strain NG60-93 $(0.8 \%, w / w)$.

\section{Mycelial fatty acids}

The results of the GLC analysis of methyl esters of fatty acids extracted from mycelium grown on the surface of CM and MM medium are presented in Table 1. Under these conditions, strain $\mathrm{CC} 1$ contained markedly higher concentrations of alkenic fatty acids $(18: 1 ; 18: 2)$ and the amount of isopalmitic acid $(i 16: 0)$ relative to 12 -methyltetradecanoic acid $(a 15: 0)$ was also increased. Differences in the ratio of $a 15: 0$ to $i 16: 0$ were also found during submerged culture in SM medium (Table 2). These investigations were extended to three other strains of $S$. hygroscopicus JA6599 yielding either high (NG33-354, R27-158) or low (wild-type strain) amounts of turimycin. All of them were capable of forming aerial mycelium $\left(\mathrm{Amy}^{+}\right)$. These $\mathrm{Tur}^{+} \mathrm{Amy}^{+}$ strains contained almost equal portions of $a 15: 0$ and $i 16: 0$, whereas $\mathrm{CCl}$ possessed a drastically

Table 1. Relative proportions $(\%)$ of fatty acids from mycelia from agar plate cultures of strains NG60-93 and CC1 grown for $8 \mathrm{~d}$ on CM and MM medium

\begin{tabular}{|c|c|c|c|c|c|c|c|c|c|c|c|c|}
\hline Medium & Strain & $i 14: 0$ & $14: 0$ & $a 15: 0$ & $i 16: 0$ & $16: 0$ & $\begin{array}{c}16: 1 / \\
a 17: 0\end{array}$ & $18: 0$ & $18: 1$ & $18: 2$ & UI & $\frac{a 15: 0}{i 16: 0}$ \\
\hline $\mathbf{M M}$ & $\begin{array}{l}\text { NG60-93 } \\
\mathrm{CC} 1\end{array}$ & $\begin{array}{l}11 \cdot 2 \\
13 \cdot 8\end{array}$ & $\overline{2 \cdot 4}$ & $\begin{array}{l}34 \\
14 \cdot 6\end{array}$ & $\begin{array}{l}33 \cdot 6 \\
29\end{array}$ & $\begin{array}{r}6 \cdot 6 \\
14 \cdot 6\end{array}$ & $\begin{array}{r}12 \cdot 3 \\
7 \cdot 2\end{array}$ & $\overline{1 \cdot 6}$ & $\overline{1.6}$ & - & $\begin{array}{l}2 \cdot 0 \\
9 \cdot 7\end{array}$ & $\begin{array}{l}1.0 \\
0.5\end{array}$ \\
\hline $\mathrm{CM}$ & $\begin{array}{l}\text { NG60-93 } \\
\mathrm{CC} 1\end{array}$ & $\begin{array}{l}14 \cdot 5 \\
10 \cdot 5\end{array}$ & $\overline{3 \cdot 7}$ & $\begin{array}{l}25 \\
10 \cdot 1\end{array}$ & $\begin{array}{l}43 \\
43 \cdot 5\end{array}$ & $\begin{array}{l}9 \cdot 3 \\
5 \cdot 6\end{array}$ & $\begin{array}{l}6 \\
3\end{array}$ & $\overline{1 \cdot 5}$ & - & $\overline{5 \cdot 2}$ & $\begin{array}{l}2 \\
7 \cdot 5\end{array}$ & $\begin{array}{l}0 \cdot 6 \\
0 \cdot 23\end{array}$ \\
\hline
\end{tabular}

Abbreviations for fatty acids: $14: 0$, tetradecanoic acid; $i 14: 0,12$-methyltridecanoic acid; $a 15: 0,12$-methyltetradecanoic acid; $i 16: 0,14$-methylpentadecanoic acid (isopalmitic acid); $16: 0$, palmitic acid; $16: 1 / a 17: 0$, nonseparated peak of both hexadecenic and 14-methylhexadecanoic acids; $18: 0$, stearic acid; $18: 1$, oleic acid; $18: 2$, linoleic acid; UI, unidentified peak with longer retention time than $18: 2$. 


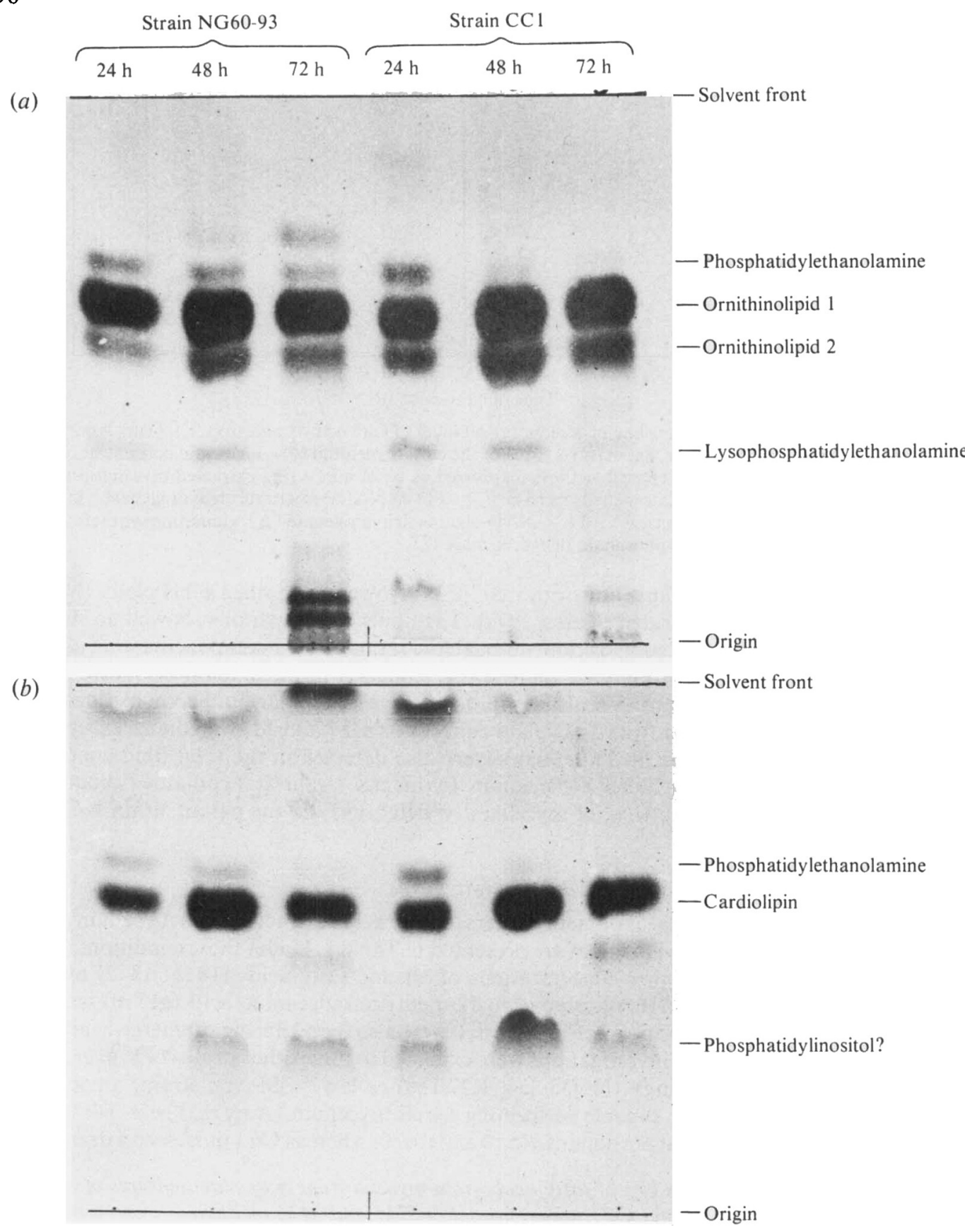

Fig. 2. TLC separation of mycelial lipids of strains NG60-93 and $\mathrm{CCl}$ grown on SM medium: (a) aminolipids (ninhydrin stain);(b) phospholipids (Vaskovski's stain). Each track corresponds to $0 \cdot 1 \mathrm{mg}$ of lipid sample.

reduced amount of the $a 15: 0$. Only minor differences were observed for the other fatty acids present. An additional unidentified fatty acid (with a longer retention time than $18: 2$ ), present in all strains, was believed to be a substituent of the ornithinolipids which are known to contain unusual hydroxy fatty acids (Batrakov \& Bergelson, 1978). In other experiments, the total lipids of $72 \mathrm{~h}$ cultures of strains NG60-93 and $\mathrm{CCl}$ were separated into non-polar (neutral) lipids (25\% of the total lipids) and polar lipids (phospholipids and ornithinolipids, $75 \%$ ) by column chroma- 
Table 2. Relative proportions (\%) of fatty acids from mycelia of strains JA6599 (wild-type), NG33-354, R27-158, NG60-93 and CCl during growth on SM medium

\begin{tabular}{|c|c|c|c|c|c|c|c|c|c|c|c|c|}
\hline Strain & $\begin{array}{c}\text { Time } \\
\text { (h) }\end{array}$ & $14: 0$ & $i 14: 0$ & $a 15: 0$ & $i 16: 0$ & $16: 0$ & $\begin{array}{r}16: 1 / \\
a 17: 0\end{array}$ & $18: 0$ & $18: 1$ & $18: 2$ & UI & $\frac{a 15: 0}{i 16: 0}$ \\
\hline NG60-93 & $\begin{array}{l}24 \\
48 \\
72\end{array}$ & $\begin{array}{l}5 \\
2 \cdot 8 \\
1 \cdot 7\end{array}$ & $\begin{array}{l}2 \\
\text { tr. } \\
\text { tr. }\end{array}$ & $\begin{array}{l}25 \cdot 5 \\
23 \cdot 6 \\
12 \cdot 1\end{array}$ & $\begin{array}{l}20 \cdot 5 \\
21 \cdot 9 \\
10\end{array}$ & $\begin{array}{l}9 \\
9 \cdot 8 \\
6.9\end{array}$ & $\begin{array}{l}14 \\
9 \cdot 8 \\
4 \cdot 5\end{array}$ & $\begin{array}{l}2 \\
1 \cdot 2 \\
2\end{array}$ & $\begin{array}{c}2 \\
6 \cdot 9 \\
10\end{array}$ & $\begin{array}{l}10 \\
10 \cdot 9 \\
14\end{array}$ & $\begin{array}{l}10 \\
12 \cdot 7 \\
38\end{array}$ & $\begin{array}{l}1.24 \\
1.07 \\
1.21\end{array}$ \\
\hline $\mathrm{CCl}$ & $\begin{array}{l}24 \\
48 \\
72\end{array}$ & $\begin{array}{l}4 \cdot 3 \\
2 \\
1.7\end{array}$ & $\begin{array}{l}1.4 \\
\text { tr. } \\
\text { tr. }\end{array}$ & $\begin{array}{l}9 \cdot 5 \\
8 \cdot 1 \\
6 \cdot 7\end{array}$ & $\begin{array}{l}29 \cdot 4 \\
25 \cdot 2 \\
29 \cdot 6\end{array}$ & $\begin{array}{r}9 \cdot 2 \\
12 \cdot 3 \\
4 \cdot 8\end{array}$ & $\begin{array}{l}14 \cdot 2 \\
20 \\
11 \cdot 6\end{array}$ & $\begin{array}{l}1.9 \\
\text { tr. } \\
\text { tr. }\end{array}$ & $\begin{array}{l}6 \cdot 7 \\
4 \cdot 7 \\
6.2\end{array}$ & $\begin{array}{r}12 \\
4 \cdot 6 \\
6 \cdot 4\end{array}$ & $\begin{array}{l}12 \\
23 \cdot 2 \\
33 \cdot 2\end{array}$ & $\begin{array}{l}0 \cdot 34 \\
0 \cdot 32 \\
0 \cdot 22\end{array}$ \\
\hline NG33-354 & $\begin{array}{l}24 \\
48 \\
72\end{array}$ & $\begin{array}{l}5.9 \\
7 \cdot 1 \\
4 \cdot 9\end{array}$ & $\begin{array}{l}1.9 \\
\text { tr. } \\
\text { tr. }\end{array}$ & $\begin{array}{l}26 \cdot 9 \\
38 \cdot 4 \\
33\end{array}$ & $\begin{array}{l}21 \cdot 7 \\
25 \cdot 6 \\
25 \cdot 8\end{array}$ & $\begin{array}{r}12 \cdot 3 \\
12 \cdot 1 \\
9 \cdot 9\end{array}$ & $\begin{array}{r}8 \cdot 6 \\
10 \cdot 6 \\
13 \cdot 2\end{array}$ & $\begin{array}{l}4 \cdot 2 \\
\text { tr. } \\
\text { tr. }\end{array}$ & $\begin{array}{l}6 \cdot 2 \\
\text { tr. } \\
\text { tr. }\end{array}$ & $\begin{array}{l}2 \cdot 4 \\
1 \\
1\end{array}$ & $\begin{array}{r}10 \\
5 \\
12\end{array}$ & $\begin{array}{l}1.23 \\
1.50 \\
1.28\end{array}$ \\
\hline R27-158 & $\begin{array}{l}24 \\
48 \\
72\end{array}$ & $\begin{array}{l}8 \cdot 1 \\
2 \cdot 6 \\
4 \cdot 9\end{array}$ & $\begin{array}{l}0.5 \\
\text { tr. } \\
\text { tr. }\end{array}$ & $\begin{array}{l}30 \\
13.6 \\
33.6\end{array}$ & $\begin{array}{l}20 \\
15 \cdot 2 \\
23 \cdot 4\end{array}$ & $\begin{array}{r}20 \cdot 6 \\
14 \cdot 7 \\
7 \cdot 6\end{array}$ & $\begin{array}{r}8 \cdot 9 \\
9 \cdot 2 \\
12 \cdot 7\end{array}$ & $\begin{array}{l}1 \cdot 2 \\
3 \cdot 4 \\
1 \cdot 4\end{array}$ & $\begin{array}{l}1 \cdot 8 \\
9 \cdot 2 \\
4 \cdot 3\end{array}$ & $\begin{array}{r}3 \cdot 1 \\
16 \cdot 5 \\
4 \cdot 3\end{array}$ & $\begin{array}{r}6 \\
16 \cdot 5 \\
7 \cdot 3\end{array}$ & $\begin{array}{l}1.50 \\
0.90 \\
1.43\end{array}$ \\
\hline JA6599 & $\begin{array}{l}24 \\
48 \\
72\end{array}$ & $\begin{array}{l}4 \cdot 7 \\
6 \cdot 7 \\
4\end{array}$ & $\begin{array}{l}\text { tr. } \\
\text { tr. } \\
\text { tr. }\end{array}$ & $\begin{array}{l}18 \\
27 \cdot 9 \\
22 \cdot 4\end{array}$ & $\begin{array}{l}16 \cdot 2 \\
25 \cdot 1 \\
32\end{array}$ & $\begin{array}{l}29 \cdot 8 \\
15 \cdot 7 \\
12 \cdot 5\end{array}$ & $\begin{array}{r}5 \cdot 1 \\
9 \cdot 9 \\
16 \cdot 2\end{array}$ & $\begin{array}{l}4 \cdot 4 \\
2 \cdot 4 \\
\text { tr. }\end{array}$ & $\begin{array}{l}5 \cdot 8 \\
1.9 \\
2 \cdot 9\end{array}$ & $\begin{array}{l}5 \cdot 1 \\
0 \cdot 6 \\
2 \cdot 7\end{array}$ & $\begin{array}{l}11 \cdot 1 \\
10 \\
7 \cdot 6\end{array}$ & $\begin{array}{l}1 \cdot 11 \\
1 \cdot 11 \\
0.70\end{array}$ \\
\hline
\end{tabular}

Abbreviations for fatty acids as in Table $1 ;$ tr., trace.

tography on silica gel. The ratio of $a 15: 0$ to $i 16: 0$ was particularly low in the polar lipids fraction of strain $\mathrm{CCl}$ ( $a 15: 0 / i 16: 0$ was 0.5 for the neutral lipids and 0.15 for the polar lipids).

\section{DISCUSSION}

Our results demonstrate that the lipid composition of the Tur $^{-} \mathrm{Amy}^{-}$derivative $\mathrm{CCl}$ differs from that of its parent strain NG60-93. This raises the possibility that concomitant changes of membrane-associated functions may be responsible for alteration of the life cycle of these organisms. Alterations of lipid composition have been observed in mutants of hygromycinproducing Streptomyces hygroscopicus obtained by treatment with acridine orange or after spontaneous degeneration (Pronina et al., 1980). Further, a great number of sporulation mutants of Bacillus species (Schaffer et al., 1972) are known to have an altered lipid composition. Our results also suggest that changes of membrane composition correspond to the inability of streptomyces mycelia to differentiate (Kalakoutski \& Agre, 1977; Ensign, 1978). On the basis of the supposed plasmid involvement in the control of differentiation processes in S. hygroscopicus (Roth \& Noack, 1982), it appears likely that this plasmid might be linked with the regulation of membrane composition. The altered ratio of $a 15: 0$ to $i 16: 0$ fatty acids in the derivative $\mathrm{CC} 1$ compared with the original strain is consistent with the view that there are alterations in the production of the precursors 2-methylbutyryl-coenzyme A and isobutyryl-coenzyme A (Machtinger \& Fox, 1973; Murray \& Magee, 1972). Both precursors are known to be produced via the degradation of methyl-branched amino acids. The findings support the view that the observed alterations of fatty acid composition during growth on chemically defined medium can be due to peculiar changes in either the formation of valine and isoleucine or in the structure and function of the common ketoacid dehydrogenase complex which is linked with their catabolism (Willecke \& Pardee, 1971).

The authors gratefully acknowledge the technical assistance of Mrs C. Wentzke, K. Gaube, G. Bergter and R. Pascholdt.

\section{REFERENCES}

ARX, E. von \& NeHER, R. (1963). Eine multidimensionale Technik zur chromatographischen Identifizierung von Aminosäuren. Journal of Chromatography 12, 329-341.
Batrakov, S. G. \& Bergelson, L. D. (1978). Lipids of streptomycetes. Structural investigation and biological interrelation. Chemistry and Physics of Lipids 21, 1-29. 
BERGMEYER, H. U. (1970). Malat-Dehydrogenase. UVTest. In Methoden der Enzymatischen Analyse, pp. 446-447. Edited by $H$. U. Bergmeyer. Berlin: Akademie-Verlag.

BERNT, E. \& BERGMEYER, H. U. (1970). IsocitratDehydrogenase. UV-Test. In Methoden der Enzymatischen Analyse, pp. 587-590. Edited by H. U. Bergmeyer. Berlin: Akademie-Verlag.

Chater, K. F. (1979). Some recent developments in streptomyces genetics. In Genetics of Industrial Microorganisms, pp. 123-133. Edited by O. K. Sebek \& A. I. Laskin. Washington, D.C.: American Society for Microbiology.

ENsign, J. C. (1978). Formation, properties and germination of actinomycetes spores. Annual Review of Microbiology 32, 185-219.

HoPwOOD, D. A. (1978). Extrachromosomally determined antibiotic production. Annual Review of Microbiology 32, 373-392.

Kalakoutski, L. V. \& Agre, N. S. (1977). Comparative aspects of development and differentiation in actinomycetes. Bacteriological Reviews 40, 469524.

KATES, M. (1972). Techniques in lipidology. In Laboratory Techniques in Molecular Biology and Biochemistry, pp. 275-600. Edited by T. S. Work \& E. Work. Amsterdam: North Holland Publishing Co.

KohlHaW, G., DrÄGERT, W. \& HolzeR, H. (1965). Parallel-Repression der Synthese von GlutaminSynthetase und DPN-abhängiger Glutamat-Dehydrogenase in Hefe. Biochemische Zeitschrift 341, 224 238.

Konova, I. V., Kasimbekova, C. K., Mitjushina, L. L., Batrakov, S. G. \& Bechterova, M. N. (1978). Influence of phosphate on composition of polar lipids from Actinomyces olivaceus. Izvestiya Akademii Nauk SSSR, Seriya biologitcheskaya 2, 285-291.

LÖHR, G. W. \& WALLER, H. D. (1970). Glucose-6phosphat-Dehydrogenase. In Methoden der Enzymatischen Analyse, pp. 599-606. Edited by H. U. Bergmeyer. Berlin: Akademie-Verlag.
MachtingER, N. A. \& Fox, C. F. (1973). Biochemistry of bacterial membranes. Annual Review of Biochemistry 42, 575-600.

Murray, W. C. \& Magee, W. L. (1972). Phospholipid metabolism. Annual Review of Biochemistry 41, 121160.

ORANISHI, M. (1979). Plasmids and antibiotic synthesis in streptomycetes. In Genetics of Industrial Microorganisms, pp. 134-140. Edited by O. K. Sebek \& A. I. Laskin. Washington, D.C.: American Society for Microbiology.

Pronina, M. I., Efimova, T. P., Zhokova, R. A., Motovilova, T. G., Pechatnikova, I. S. \& TEREsIN, I. M. (1980). Morphological and biochemical characteristics of mutants of Streptomyces hygroscopicus under the action of acridine orange and mitomycin C. Mikrobiologiya 49, 302-307.

RoTH, M. \& NoACK, D. (1982). Genetic stability of differentiated functions in Streptomyces hygroscopicus in relation to conditions of continuous culture. Journal of General Microbiology 128, 107-114.

Roth, M., NoACK, D. \& ReINHARdT, G. (1982). Properties of non-differentiating derivatives of Streptomyces hygroscopicus. Journal of General Microbiology 128, 2687-2691.

SChaffer, P., Guespin-Machel, J., CaMi, B., RouGaRD, J. F. \& MazliaK, P. (1972). Membrane changes in some pleiotropic sporulation mutants of Bacillus subtilis. In Spore Research 1971, pp. 333-334. Edited by A. N. Barker, G. W. Gould \& J. L. Wolf. London: Academic Press.

ScHMIDT, E. (1970). Glutamat-Dehydrogenase. UVTest. In Methoden der Enzymatischen Analyse, pp. 609-613. Edited by H. U. Bergmeyer. Berlin: Akademie-Verlag.

Wiame, J. M., Pierard, A. \& Ramos, F. (1962). L-Alanine dehydrogenase from Bacillus subtilis. Methods in Enzymology 5, 673-677.

Willecke, K. \& Pardee, A. B. (1971). Fatty acidrequiring mutant of Bacillus subtilis defective in branched chain $\alpha$-ketoacid dehydrogenase. Journal of Biological Chemistry 246, 5264-5272. 